\title{
Aprendizagem Baseada em Problemas: um método de ensino-aprendizagem e suas práticas educativas.
}

\author{
Eli Borochovicius* \\ Jussara Cristina Barboza Tortella**
}

\section{Resumo}

O método da Aprendizagem Baseada em Problemas tem como propósito tornar o aluno capaz de construir o aprendizado conceitual, procedimental e atitudinal por meio de problemas propostos que o expõe a situações motivadoras e o prepara para o mundo do trabalho. Analisamos o desenvolvimento do método no curso de administração de uma universidade do estado de São Paulo, especificamente, nas disciplinas de finanças, que envolvem conceitos teóricos e matemáticos. Utilizamos quatro instrumentos na coleta de dados: análise documental; entrevistas com professores, ex-diretores e o diretor em exercício; questionário com alunos e observação. Para o presente artigo trazemos informações sobre os pressupostos teóricos do referido método, a análise documental e entrevistas com o total de professores do eixo temático de finanças, que trouxeram as suas experiências de sala de aula. Os resultados obtidos indicam que é necessário o aprimoramento na prática docente.

Palavras-chave: avaliação. ensino superior. ABP.

\section{Introdução}

As transformações que vêm ocorrendo na sociedade brasileira provocam impactos significativos nas escolas e na relação ensino-aprendizagem. Tais transformações exigem mudanças que permitam trazer respostas rápidas e eficazes às demandas dos discentes, que vivem em um ambiente cada vez mais concorrido, com a intensificação da imprevisibilidade no mundo dos negócios e com a evolução tecnológica.

Uma nova configuração de ingressantes universitários, formados por uma geração cuja informação é apresentada por meio de uma grande variedade de ferramentas e em volume exagerado, chega às instituições de ensino superior para serem

*Mestre PUC-Campinas. E-mail: boro@puc-campinas.edu.br

**Doutora PUC-Campinas. E-mail: atortella@uol.com.br 
preparados para o mercado profissional no qual desejam atuar. Trata-se da Geração Y, também conhecida como Geração Millennials ou ainda Geração da Internet, indivíduos que nasceram entre o início da década de 80 e o final da década de 90, cujo crescimento se deu paralelo à evolução do mundo digital.

A geração Y é formada por indivíduos empreendedores, independentes, com alta capacidade para lidar com as tecnologias de ponta e valorizam os desafios (MUNRO, 2009; VIANA, 2011). Zucco (2010) diz que o perfil desta geração é de pessoas autoconfiantes e otimistas quanto ao futuro; são agitados, inquietos, ansiosos e impacientes; desenvolvem múltiplas tarefas ao mesmo tempo; recebem muitas informações dificultando a correlação de conteúdos, desenvolvendo uma visão desordenada e fragmentada das mesmas e buscam equilíbrio entre suas obrigações profissionais e seus desejos pessoais.

A geração Y é a que está ocupando as cadeiras nas universidades e assim como houve uma transformação do indivíduo, é possível observar a tendência de mudanças também nas escolas, nos currículos e no processo ensino-aprendizagem. Os jovens universitários da geração $Y$ se beneficiam da quantidade e da velocidade da informação com os recursos da internet e desejam interagir com a realidade, representando um desafio às aulas expositivas tradicionais, ainda que apoiadas por recursos audiovisuais (NEVES, 2006).

A nossa sociedade nos impõe diferentes exigências, especialmente na área educacional, em que tudo muda rapidamente. As informações são transmitidas e conhecidas de maneira quase instantânea e passaram a fazer parte do ambiente escolar, causando preocupação nos professores sobre o seu papel nessa nova realidade (HARGREAVES, 2011).

De acordo com Soares (2008), as Instituições de Ensino Superior buscam atender aos anseios dessa nova geração de estudantes por meio de metodologias, métodos e meios pedagógicos, garantindo qualidade e efetividade do ensino. Uma possibilidade é a utilização de métodos pedagógicos que permitam ao estudante desempenhar um papel mais ativo e garantindo-lhe maior autonomia no processo de aprendizagem. Segundo Candau (2000, p. 13): “A escola precisa ser espaço de formação de pessoas capazes de serem sujeitos de suas vidas, conscientes de suas opções, valores e projetos de referência e atores sociais comprometidos com um projeto de sociedade e humanidade". 
Há muito se discute sobre os propósitos do Ensino Superior e sobre a eficiência dos métodos de ensino e aprendizagem dentro da universidade, considerando, em especial, a complexidade das exigências provenientes de um mercado cada vez mais globalizado e competitivo (FLINT, 2007). As aulas expositivas têm estado mais voltadas para a transmissão de conhecimentos, nas quais o conteúdo a ser aprendido é apresentado pelos docentes aos discentes em sua forma final, privando-os do exercício das habilidades intelectuais mais complexas como a aplicação, análise, síntese e julgamento (GODOY, 2000).

De acordo com Pereira (1998), para que a aprendizagem ocorra, ela precisa ser necessariamente transformacional, exigindo do professor uma compreensão de novos significados, relacionando-os às experiências prévias e às vivências dos alunos, permitindo a formulação de problemas que estimulem, desafiem e incentivem novas aprendizagens. Nesse contexto, surge a possibilidade da aplicação da Aprendizagem Baseada em Problemas (ABP), com o propósito de auxiliar o discente no conhecimento do conteúdo teórico, fortalecer a sua capacidade de resolver problemas e envolvê-lo no aprendizado (LEVIN, 2001).

Desenvolvemos uma pesquisa que objetivou avaliar a aplicação da ABP no curso de Administração de uma universidade do interior do estado de São Paulo. Foram utilizadas várias técnicas de coleta de dados, como: 1. Pesquisa bibliográfica com a finalidade de apropriação das informações a respeito da ABP; 2. Pesquisa documental para tomar conhecimento do Projeto Pedagógico e de como a instituição pesquisada aplica o método por meio de relatórios padronizados; 3. Entrevista com os ex-diretores para saber o que motivou a escolha do método ABP para o curso de administração; 4. Entrevista com o atual diretor visando a obtenção de dados atualizados a respeito da aplicação da ABP na instituição pesquisada e as perspectivas para os próximos anos. 5. Entrevista com o total de professores do eixo temático de finanças, que trouxeram as suas experiências de sala de aula; 6. Questionário com 50 discentes que puderam expressar, ainda que de forma mais limitada, as suas vivências; 7. Observação visando articular as informações provenientes de docentes e discentes, além da reflexão sobre a própria prática, dado que o autor faz parte do grupo de professores que trabalham com o método da ABP.

Neste trabalho trazemos dados parciais dessa pesquisa e discutimos os aspectos conceituais da ABP e suas contribuições para o ensino superior, mais especificamente para a disciplina de finanças do curso de Administração, a 
partir da pesquisa bibliográfica (1), documental (2) e entrevista com o total de professores do eixo temático de finanças, que trouxeram as suas experiências de sala de aula (5). Para a pesquisa foram utilizados os métodos bibliográfico, descritivo e exploratório, com abordagem de investigação qualitativa. A pesquisa qualitativa não é padronizada, pretendendo interpretar o sentido das ações a partir do significado que as pessoas atribuem ao que falam e fazem, considerando a liberdade e a vontade humana (CHIZZOTTI, 2010).

Como destacado em orientações sobre o estudo descritivo, realizamos descrições registros, análises e interpretações dos fenômenos estudados. (BEST, 1972 apud MARCONI; LAKATOS, 2007) procurando examinar o tema de pesquisa pouco estudado e ampliando os estudos já existentes, característica dos estudos exploratórios. (SAMPIERI; COLADO; LUCIO, 2006). Para Gil (2002, p. 40), as pesquisas exploratórias "tem como objetivo principal o aprimoramento de ideias".

Para a pesquisa bibliográfica consideramos pesquisas anteriores para apropriação das informações daquilo que já fora produzido sobre o assunto (RUIZ, 2002) e nos pautamos em Marconi e Lakatos (2007, p. 71) que determinam que "a pesquisa bibliográfica não é mera repetição do que já foi dito ou escrito sobre certo assunto, mas propicia o exame de um tema sob novo enfoque ou abordagem, chegando a conclusões inovadoras".

Apesar da subjetividade dos documentos analisados, consideramos que eles se constituíram em uma importante fonte de dados já que normalmente resistem ao tempo. Assim, a pesquisa documental contou com a reunião de materiais disponibilizados pela instituição pesquisada que foram organizados e "reelaborados de acordo com os objetos da pesquisa". (GIL, 2002, p. 45).

Como mencionado, para o presente artigo trazemos a fundamentação teórica e pedagógica da ABP e dados da análise documental que avaliou a coerência entre os pressupostos teóricos e a aplicação do método, a partir da análise do Projeto Pedagógico e dos instrumentos didáticos atualmente empregados para o desenvolvimento do método pela instituição pesquisada.

Na primeira parte trazemos a parte histórica da $\mathrm{ABP}$ bem como os encaminhamentos procedimentais para sua aplicação. Na segunda parte do texto apresentamos as contribuições dos estudos sobre a prática pedagógica, destacando os processos 
de ensino e aprendizagem, o papel do aluno e do docente, com foco na ABP. Destacamos, no terceiro tópico, os dados da análise documental e por fim, as considerações finais.

\section{Aprendizagem baseada em problemas: breve histórico e pressupostos teóricos}

John Evans assumiu em 1965 a reitoria da escola de medicina de McMaster, na cidade de Hamilton, província de Ontário, no Canadá e tinha o desejo de mudar a forma como a medicina estava sendo ensinada, certo de que o desafio da inovação só poderia se tornar realidade em uma escola que não estivesse impregnada de tradições. Ele selecionou quatro jovens médicos que compactuavam de seu pensamento para formar o Comitê de Educação da McMaster. Foram conhecidos como os Cinco Fundadores.

$\mathrm{O}$ intuito do Comitê era permitir que seus estudantes de medicina tivessem habilidades para resolver problemas e juntar, avaliar, interpretar e aplicar uma grande quantidade de informações que trouxessem melhores respostas aos pacientes. Saíram em busca de inspiração, visitando algumas escolas e um dos modelos que mais os agradou foi o método de estudo de casos da Harvard Business School, nos Estados Unidos, que envolvia pequenos grupos discutindo casos práticos. (ATRIE et al., 2009). As propostas educacionais, no entanto, eram diferentes. Em Harvard, as discussões dos casos ocorriam nos últimos períodos dos cursos, quando os alunos já tinham conhecimento de grande parte do conteúdo e a concepção curricular da McMaster era desenvolver os conceitos depois de os estudantes receberem uma situação problema (MAMEDE, 2001).

Outro modelo que inspirou a McMaster foi aplicado em 1952 pela Faculdade de Medicina da Case Western Reserve University de Ohio, Estados Unidos. Nele havia quatro particularidades: 1 . Interdisciplinaridade; 2 . Menor número de docentes; 3. Maior número de disciplinas optativas; 4 . Controle curricular feito por comissões temáticas. O grupo que consolidou o método da ABP na McMaster buscava mudanças no processo ensino-aprendizagem, mas sem clareza de quais seriam elas (BRANDA, 2009).

$\mathrm{Na}$ década 70 do século passado, a ABP foi introduzida na Universidade de Maastricht, na Holanda, em Newcastle na Austrália e Harvard, nos Estados Unidos. No Brasil, foi implantado na Escola de Saúde Pública do Ceará em 
1993, na Faculdade de Medicina de Marília (FAMEMA) em 1997 e no curso de Ciências Médicas da Universidade de Londrina (UEL) em 1998 (CARLINI, 2006). Atualmente vem sendo empregado em diversas universidades do mundo, assim como no Brasil, não apenas na área da saúde, mas também em outras áreas como engenharia, enfermagem, pedagogia e também na administração (RIBEIRO, 2008).

A ABP tem como premissa básica o uso de problemas da vida real para estimular o desenvolvimento conceitual, procedimental e atitudinal do discente.

Para Penaforte (2001), fazer uma reconstrução histórica de ideias que não seguem uma cronologia precisa é uma tentativa não imune ao risco de incorrer em incerteza e precisão, mas as proposições existentes apontam para Bruner e Dewey como a base intelectual para a ABP. Schmidt (1993 apud RIBEIRO, 2005) confirma a premissa, pois acredita que a ABP é baseada em Bruner, para quem a motivação impulsiona o indivíduo a conhecer melhor o mundo e também baseado na aprendizagem autônoma de Dewey com o uso de problemas antecedendo o conceito, ressaltando a importância de se aprender com eventos reais.

Jerome Seymour Bruner, psicólogo americano, foi o principal proponente do modelo da Aprendizagem pela Descoberta (APD), que consistia na utilização de problemas com discussão em grupos para desenvolver habilidades de raciocínio e motivar os discentes em aprender com situações da realidade, facilitando a assimilação e a retenção da informação (PENAFORTE, 2001). Para Bruner (1976), a aprendizagem se dá em três processos, que ocorrem quase que simultaneamente: 1. Aquisição de nova informação, confirmando ou contradizendo a informação previamente estabelecida pelo aluno; 2. Transformação da informação adaptando-a a novas ideias; 3 . Avaliação da adequação da informação. Para que esses processos se desencadeiem é importante que haja a vontade do aluno em aprender, que pode ser movido pela curiosidade e interesse pela descoberta. Ser desafiado por um problema permite que o aluno busque informações, as confronte e descubra novas informações, consolidando a aprendizagem.

As concepções de Bruner, segundo Penaforte (2001), podem ser consideradas precursoras imediatas da ABP, porém é necessário voltar no tempo para analisar a teoria do conhecimento de Dewey. Nas primeiras décadas do século XX, nascem na Europa propostas pedagógicas de um movimento renovador conhecido por Escola Nova. A base das propostas é um processo educativo guiado pela satisfação em 
aprender o conteúdo de forma ativa, desenvolvendo as funções morais e intelectuais do indivíduo, descaracterizando o processo de educação de cunho estritamente memorístico, modelo que prevalecia naquele período (SALVADOR, 1999).

Segundo Andrade e Cunha (2011), John Dewey não rejeitava a existência de mecanismos biológicos na formação do indivíduo, mas enfatizava o poder da relação social e os vínculos socialmente estabelecidos na vida prática. Entendia que, historicamente, as atividades coletivas colocaram as pessoas diante de situações semelhantes, gerando sentimentos análogos e formando uma consciência coletiva, defendendo que a natureza humana é predominantemente - não exclusivamente - social. De acordo com Dewey (1959, p. 153), para a educação: "A experiência é, primariamente, uma ação ativo-passiva; não é, primariamente, cognitiva. Mas, a medida do valor de uma experiência reside na percepção das relações ou continuidades a que nos conduz". A educação é um processo de reorganização da experiência e de reconstrução pela reflexão, visando melhorar, pela inteligência, a qualidade das experiências futuras (DEWEY, 1978).

Para Dewey, o conhecimento se inicia por um problema e se encerra com a resolução dele, passando por um processo indagativo e reflexivo, por meio de uma sequência ordenada e consecutiva de ideias. O pensamento reflexivo se inicia com questionamentos, que originam o ato de pensar e se encerra com a realização de uma pesquisa, cujo objetivo é encontrar respostas para as indagações. O processo de investigação ocorre considerando os seguintes passos: 1. Apresentação de um problema; 2. Identificação do problema; 3. Sugestão de solução; 4. Experimentação; 5. Solução (TIBALLI, 2003).

Considerando os pressupostos da $\mathrm{ABP}$, existe uma coerência direta com os apontamentos de John Dewey, em especial quanto ao pensamento reflexivo e ao processo de investigação. A situação-problema, que dá início ao processo, traz uma situação próxima da realidade que o aluno enfrentará em sua profissão, sem resposta pronta, causando a dúvida que é própria da experiência reflexiva.

Dewey (1976), ao confirmar ser próprio do ser-humano pensar em termos de oposições extremadas, de polos opostos, desconsiderando possibilidades intermediárias, critica ser histórica a ideia de que a educação se dá de dentro para fora e a formação de fora para dentro, em que teoria é educação e a prática é formação. Para o autor, não há uma dicotomia entre teoria e prática dado que a relação ensino-aprendizagem se dá a partir da ação ativa do educando. 
Todo o ato de pensar é original e favorece a descoberta, criando prazer da produtividade intelectual, diferentemente do armazenamento de informações transmitidas por terceiros. É necessário que sejam proporcionadas condições que estimulem o pensamento para que o aprendizado ocorra. (DEWEY, 1959).

Após o entendimento de como surgiu a ABP e seus pressupostos teóricos, discutimos no próximo tópico os aspectos dessa metodologia relacionados com as práticas educativas.

\section{A aprendizagem baseada em problemas e as práticas educativas}

O objetivo principal da prática educativa é criar possibilidades ao educando de aprender e consequentemente se desenvolver pela ampliação permanente da consciência, como sujeito e como cidadão. A formação pessoal sem a perspectiva da cidadania, por um lado, conduz ao individualismo, por outro lado, a formação do cidadão sem a perspectiva do sujeito conduz a uma sociedade autoritária. "O ensino e aprendizagem dos conhecimentos elaborados e em elaboração pela ciência, pela filosofia e pelas artes são recursos fundamentais para a ampliação da consciência" (LUCKESI, 2011, p.55).

Originalmente, ensinar significa esclarecer alguém sobre aquilo que não conhece, modificando ou enriquecendo o seu comportamento por intermédio da aprendizagem. A aprendizagem pode ser entendida como uma mudança de comportamento provocada pela experiência de terceiros, reelaborada pelo próprio sujeito e não pela repetição ou pela associação automática de estímulos e respostas. Na construção de conhecimentos, a aprendizagem humana não se explica pela integridade biológica ou pela exposição direta a objetos, acontecimentos, atitudes e situações, mas emerge por uma relação indivíduomeio que é mediada por outro indivíduo mais experiente, promovendo o desenvolvimento cognitivo crítico e criativo (FONSECA, 1998). Meirieu (1999) diz que aprender não significa apenas prestar atenção no conhecimento que está sendo recebido, ler e escutar. Da mesma forma não se aprende pela pura repetição ou por imitação, pois desta forma há apenas uma descrição de comportamentos. É preciso, no entanto, efetuar operações mentais sobre um novo conceito e integrá-lo em uma estrutura antiga, modificando-a. 
De acordo com Mamede (2001), a perspectiva da ABP é delineada nos princípios derivados da psicologia cognitiva, caracterizada como uma forma de aprendizagem e instrução colaborativa, construtivista e contextual. Levin (2001) afirma que a ABP está relacionada com a teoria construtivista da aprendizagem.

No processo de construção de novos conhecimentos o conteúdo é um aspecto a ser considerado. Ao questionarmos "o que o aluno deve saber?", "o que se deve saber fazer?" e "como se deve ser?", estamos tratando de aprendizagens de conteúdos conceituais, procedimentais e atitudinais, respectivamente. Entende-se por conteúdo conceitual o conhecimento de um conjunto de fatos, acontecimentos, situações, dados e fenômenos concretos. Para ensinar os conteúdos conceituais é possível trabalhar com um modelo expositivo sem excessos de informação, estudos individuais com o estímulo no desenvolvimento de exercícios e prova, evitando que as aprendizagens estejam desvinculadas da capacidade de utilização do conhecimento em diversos contextos (ZABALA, 1998).

Conteúdo procedimental é a tipologia dada a um conjunto de ações ordenadas dirigidas a um determinado objetivo, como regras, técnicas, métodos, estratégias, procedimentos e habilidades. Essas ações são aprendidas pelo fazer, mas apesar da obviedade, nas propostas de ensino com aulas expositivas não se cria essa oportunidade para o discente. É necessário exercitar as ações continuamente e tantas vezes quantas forem necessárias para se chegar ao domínio do conteúdo, mas a pura repetição, por si só, não traz resultados satisfatórios. A estratégia mais apropriada para trabalhar com os conceitos procedimentais é a de proporcionar ajuda ao discente ao longo das diferentes ações, reduzindo o apoio progressivamente com atividades de trabalho independente, de sorte que possam demonstrar suas competências no domínio do conteúdo aprendido (ZABALA, 1998).

O conteúdo atitudinal faz referência aos valores, como princípios ou juízo de conduta, atitudes e normas como regras de comportamento a serem seguidas dentro de uma sociedade e são configurados por componentes cognitivos, afetivos e comportamentais. Solidariedade, respeito ao próximo, interação com os professores e demais alunos, responsabilidade, correto uso da liberdade e cooperação são alguns exemplos de conteúdos atitudinais. As atitudes podem ser aprendidas em diferentes graus, sendo o primeiro por simples aceitação do conhecimento, o segundo pela reflexão e conformidade e o terceiro grau pela interiorização e aceitação como base da sociedade que se vive. A participação ativa 
do discente exige um compromisso que o leve a ser protagonista de sua própria aprendizagem e agente na formulação de propostas de convivência, participando do controle dos processos e resultados (ZABALA, 1998).

O professor do Ensino Superior normalmente foca o seu trabalho no conteúdo conceitual, reduzindo o seu nível de afetividade quando comparado aos professores de níveis de ensino anteriores, causando, de certa forma, uma sensação de abandono ou de opressão (QUADROS et al., 2010).

Nesse sentido, há que se considerar que a sala de aula é um espaço de relações pedagógicas com o objetivo de crescimento individual, constituído pela diversidade e heterogeneidade de valores, ideias e crenças e voltado para a formação, vivência e convivência dos indivíduos. De acordo com Lourenço e Palma (2005), a heterogeneidade de um grupo possibilita troca de experiências, argumentações, informações e choques com diferentes pontos de vista, permitindo que as situações de conflito cognitivo contribuam para a formação do educando. Consideram que o conflito cognitivo passa a ser uma estratégia com resultados positivos no processo ensino-aprendizagem quando ele permite que haja um desequilíbrio que motive o discente a melhorar os conhecimentos que já possui.

Segundo Pozo (2002), entre trabalhar de forma individual ou realizar tarefas com a cooperação mútua, os resultados são melhores quando se favorece a interação entre os alunos. Isso acontece porque o cooperativismo costuma melhorar a orientação social e favorecer a reflexão e tomada de consciência do indivíduo.

AABP possui objetivos educacionais mais amplos, com uma base de conhecimentos estruturada em torno de problemas reais e integrada com o desenvolvimento de habilidades de aprendizagem autônoma e de trabalho em equipe, favorecendo a adaptabilidade a mudanças, habilidade na solução de problemas em situações não rotineiras, pensamento crítico e criativo, trabalho em equipe e o compromisso com o aprendizado e aperfeiçoamento contínuo (RIBEIRO, 2008). Para Tynyälä (1999 apud RIBEIRO, 2008), a ABP permite satisfazer uma formação que integre teoria à prática, promovendo o domínio do conhecimento específico e o desenvolvimento de habilidades e atitudes profissionais e cidadãs.

Trata-se de uma metodologia que visa atender não apenas às necessidades dos discentes, mas também dos docentes e da sociedade. Dos discentes, pois o método 
permite que os alunos resolvam problemas relacionados as suas futuras profissões e os estimulam a pesquisar tornando-os capazes de aprender a aprender, serem críticos e tomarem decisões. Dos docentes porque os estimulam a pesquisarem e buscarem a interdisciplinaridade, fazendo conexão daquilo que estão ensinando com uma gama de informações necessárias aos futuros profissionais. Da sociedade, pois em função da alta competitividade, concorrência e um cenário globalizado e repleto de rápidas mudanças no mundo do trabalho, recebe um profissional apto a buscar soluções condizentes com a realidade e suas necessidades.

Conforme Mamede (2001), o método da ABP se configura como uma estratégia educacional e uma filosofia curricular, em que os discentes autodirigidos constroem o conhecimento de forma ativa e colaborativa e aprendem de forma contextualizada, apropriando-se de um saber com significado pessoal. Não é um método que possa ser utilizado de forma isolada em determinadas disciplinas e está fundamentado nos princípios sobre os quais se baseia o processo de aprendizagem, com implicações e determinações sobre todas as dimensões organizacionais do processo educacional.

Neste método, o aluno precisa desenvolver a capacidade de descobrir e usar informações, construir suas próprias habilidades para resolver problemas e aprender o conteúdo necessário. O currículo que melhor prepara o futuro cidadão e profissional do mercado não é aquele somente baseado em teoria, mas o que, além dos conhecimentos teóricos, mostra como aprender por conta própria e como usar as informações que são adquiridas. Os discentes precisam de um conjunto de conhecimentos essenciais para o uso de forma eficaz na solução de problemas dentro e fora da universidade, ampliação ou melhora do seu conhecimento e desenvolvimento de estratégias para lidar com problemas futuros (DELISLE, 1997).

Considerando tais aspectos, a utilização da $\mathrm{ABP}$ no curso de administração da instituição pesquisada é coerente, pois um problema não estruturado é utilizado como início de discussão de um conceito ou conteúdo, posteriormente o docente faz um direcionamento do que é produzido pelos discentes em pequenos grupos, motivando-os a pesquisar.

Para Rodrigues e Figueiredo (1996), os tópicos a serem aprendidos devem ser identificados a partir de problemas reais ou simulados, conhecidos por situaçãoproblema e, para que os discentes os resolvam, devem recorrer aos seus conhecimentos prévios, integrando-os aos novos conhecimentos a serem adquiridos em pesquisa. Essa integração, aliada à prática, permite que haja maior retenção do conhecimento. 
Para Bridges (1992, p. 5-6), a ABP traz características como:

1. O ponto de partida para a aprendizagem é um problema (isto é, um estímulo para o qual um indivíduo não tenha uma resposta imediata); 2. O problema deve permitir que os alunos estejam aptos a enfrentar o mercado como futuros profissionais; 3 . O conhecimento que os alunos devem adquirir durante a sua formação profissional é organizada em torno de problemas em vez de disciplinas; 4. Estudantes, individualmente ou coletivamente, assumem uma importante responsabilidade pelas suas próprias instruções e aprendizagens; 5. A maior parte do aprendizado ocorre dentro do contexto de pequenos grupos em vez de exposições.

A situação-problema coloca o discente em ação de forma interativa com a realidade, que desestabiliza e reestabiliza em função das intervenções promovidas pelo docente e é nesta interação que se constrói, muitas vezes irracionalmente, a racionalidade (MEIRIEU, 1999). Pozo (2002) diz que o mais complexo não é fazer com que os discentes aprendam um determinado conceito ou procedimento dentro de um problema, mas fazer com que utilizem o problema de forma autônoma, transferindo espontaneamente para um contexto mais cotidiano. Para Carlini (2006), o problema deve ser claro e inequívoco, permitindo a identificação dos objetivos de aprendizagem e dos aspectos a serem pesquisados. Deve trazer situações semelhantes do cotidiano, gerando estímulo à pesquisa individual e debate em grupo, focando em uma situação que seja compatível com a realidade dos discentes. A estrutura do problema deve estar em consonância com o currículo, responsável por nortear a concepção dos problemas que serão apresentados.

Schmidt (1983 apud DEELMAN; HOEBERIGS, 2009) descreve uma estratégia de etapas chamada de "sete passos" com o objetivo de auxiliar os estudantes na resolução de um determinado problema, a partir do levantamento de causas, buscando analisar os processos ou princípios subjacentes dos fenômenos descritos. 1. esclarecer frases e conceitos confusos na formulação do problema; 2. definir o problema: descrever exatamente que fenômenos devem ser explicados e entendidos; 3. chuva de ideias (Brainstorming): usar conhecimentos prévios e senso comum próprios. Tentar formular o máximo possível de explicações; 4. detalhar as explicações propostas: tentar construir uma "teoria" pessoal, coerente e detalhada dos processos subjacentes aos fenômenos; 5 . propor temas para a aprendizagem 
autodirigida; 6. procurar preencher as lacunas do próprio conhecimento por meio do estudo individual; 7. compartilhar as próprias conclusões com o grupo e procurar integrar os conhecimentos adquiridos em uma explicação adequada dos fenômenos. Comprovar se sabe o suficiente. Avaliar o processo de aquisição de conhecimentos (DEELMAN; HOEBERIGS, 2009, p. 84).

Mamede (2001) descreve os sete passos desenvolvidos pelos alunos, como um ciclo de aprendizagem que se inicia em grupo, com a leitura da situação-problema proposta pelo docente. Os termos que porventura não estejam claros devem ser tratados e inteiramente compreendidos pelos participantes, havendo consenso quanto à interpretação às expressões do texto. $\mathrm{O}$ grupo deve identificar e definir os conceitos a serem investigados para posterior análise do problema, considerando os conhecimentos prévios existentes de cada membro do grupo, debatendo livremente o tema com base nas experiências individuais. O grupo estrutura e sistematiza os diversos aspectos debatidos com propostas de pesquisa, identificando os objetivos de aprendizagem. O ciclo dentro do grupo é interrompido para que, individualmente, os elementos possam pesquisar e adquirir os conhecimentos necessários para que os objetivos sejam alcançados. Uma vez que os alunos tenham encerrado o seu período de estudo individualizado, devem voltar a se reunir para socializar os resultados que foram obtidos, justificando suas análises fundamentadas na bibliografia encontrada. Por fim, o grupo deve formular uma proposta sistematizando as informações que foram anteriormente debatidas.

A adoção de uma metodologia de ensino-aprendizagem como a ABP exige não apenas uma transformação nos processos institucionais e educacionais como também uma mudança no papel dos docentes e discentes (RIBEIRO, 2008). Para Cyrino e Toralles-Pereira (2004), a ABP exige criatividade do docente, que deve se preocupar não apenas com o "que" o estudante aprende, mas especialmente com o "por que" e "como" ele aprende.

A função do docente é estimular o pensamento crítico e o autoaprendizado dos discentes, orientando-os a desenvolver o próprio processo de pensar, além de promover a cooperação mútua entre os discentes que trabalham em grupos. Deve manter o fluxo das discussões em grupo e direcioná-las ao problema evitando desvios de foco. A intervenção do docente deve estimular o grupo a pensar crítica e profundamente, questionar visando auxiliar os estudantes a descobrirem possíveis erros de concepções, detectar possíveis erros de informações e ao 
descobrir a dificuldade dos alunos em encontrar o caminho correto, prover de informações, seja com breve explicação, seja com exemplos práticos, para que o grupo retome a discussão. A observação e análise do andamento dos trabalhos é também função do docente que deve contribuir com os grupos por meio de um feedback, informando sobre a qualidade das discussões, objetivando melhorar a participação individual dos membros de cada grupo (TOMAZ, 2001).

Para Mennin et al. (2003, p. 1-2), o docente faz intervenções durante o processo de aprendizagem sem, no entanto, dar a solução do problema, usando perguntas para explorar e estimular o pensar e "desenvolver a capacidade de raciocínio, melhorar as habilidades de comunicação, adotar comportamentos e atitudes profissionais, bem como desenvolver habilidades de autoavaliação e de avaliação dos seus pares". Partindo do pressuposto de que a transformação é a essência da realidade e que a educação está em constante desenvolvimento, o professor passa a ser um orientador de experiência agindo muito mais como mediador a uma figura autoritária.

$\mathrm{O}$ aprendizado autodirecionado e o desenvolvimento autônomo do aluno são fundamentais no desenvolvimento da ABP. Desse modo, não cabe ao docente o papel de sistematizar o conhecimento necessário à análise ou resolução do problema, mas o de acompanhar o discente intervindo com informações e estabelecendo uma ponte entre os conhecimentos prévios do estudante e o novo conteúdo a ser aprendido, desafiando o aluno a pensar de forma crítica.

Para facilitar o trabalho do professor com o uso da ABP, Bridges (1992) recomenda que, ao dar ofeedback aos alunos, o docente busque apontar as forças e fraquezas do trabalho realizado, sugerir melhorias, discutir as sugestões e colocar questões para que os estudantes possam refletir.

O trabalho do docente não se restringe a atuar dentro dos grupos, cabendo a ele funções mais abrangentes dentro do processo de ensino-aprendizagem. Deve servir como um suporte para o aprendizado do aluno, tendo disponibilidade para envolver-se de maneira autêntica com eles, servir de modelo comportamental, demonstrando a realização da atividade e modelo cognitivo, verbalizando a essência do seu pensamento. A aula expositiva pode ser usada em alguns casos para prover os alunos de informações, inclusive com o uso de experiências pessoais. A elaboração e seleção de material didático como textos, livros e artigos devem ser feitas pelo docente, assim como o planejamento do curso, em conjunto 
com outros docentes de diferentes departamentos ou setores e o planejamento dos recursos de aprendizagem. Além disso, cabe ao docente avaliar os discentes e o próprio curso (TOMAZ, 2001).

Qualquer que seja a metodologia de ensino empregada, a aprendizagem é de responsabilidade do aluno, mas, na ABP, é mais nítida esta posição, uma vez que se trata de uma metodologia educacional centrada no aluno.

\section{Nossa Pesquisa}

A nossa pesquisa foi ampla, com utilização de várias técnicas de coleta de dados, e como destacado, incluindo pesquisa bibliográfica em obras nacionais e internacionais bem como artigos científicos e uma pesquisa documental que serão agora detalhados.

No levantamento bibliográfico realizada na Biblioteca Digital Brasileira de Teses e Dissertações do Ministério da Ciência e Tecnologia foram encontrados trezentos e vinte e dois trabalhos por meio da busca básica com as palavras "aprendizagem baseada problema" até o ano 2011. Ao acrescentar a palavra "administração" na consulta, foram obtidos como resposta apenas vinte e dois trabalhos, dentre eles, embora não apresente em seu título a menção da $\mathrm{ABP}$, uma única obra voltada para a área de administração. Trata-se da tese de doutorado em administração de Fabrício Sobrosa Affeldt da Universidade Federal do Rio Grande do Sul, intitulada "Desenvolvimento e aplicação de um modelo construtivista para o ensino de administração", de 2011, portanto, extremamente recente; no entanto, o trabalho não trata em essência da metodologia, mas da elaboração de um modelo construtivista para o ensino em administração.

Ao consultar pela sigla PBL, que significa Problem-Based Learning, ou Aprendizagem Baseada em Problemas ao ser traduzido para o português, foram encontrados cinquenta e seis trabalhos, dentre eles, dois trabalhos que, embora não sejam da área da administração, são de área correlata por também utilizar as disciplinas de finanças, ainda que em menor grau. O primeiro é um trabalho apresentado por Mara Alves Soares em sua dissertação de mestrado em Controladoria e Contabilidade na Universidade de São Paulo em 2008, intitulado "Aplicação do método de ensino Problem Based Learning (PBL) no curso de Ciências Contábeis: um estudo empírico" e o segundo trabalho é de Evaneide Barbosa de Oliveira, apresentado em sua dissertação de mestrado em Ciências 
Contábeis e Financeiras na Pontifícia Universidade Católica de São Paulo em 2010, intitulado "Aprendizado baseado em problemas (problem based learning): a sua importância no ensino da contabilidade". Ambos os trabalhos tratam em essência da aplicação do método, diferentemente da proposta de nossa pesquisa que avaliou o método já empregado, na concepção de docentes e discentes.

Foram pesquisadas também as obras disponíveis no banco de dados da Coordenação de Aperfeiçoamento de Pessoal de Nível Superior (CAPES), instituição que desempenha papel fundamental na expansão e consolidação da pós-graduação Stricto Sensu no Brasil. A pesquisa foi realizada por assunto, com a expressão exata "aprendizagem baseada em problema" e a consulta retornou setenta e cinco trabalhos. Dentre eles, é possível ressaltar a dissertação de mestrado em Ciências da Computação de Jefferson Treml, apresentada em 2001, na Universidade Federal de Santa Catarina, com o título "Uma Proposta DidáticoPedagógica para o Curso de Administração: aprendizagem baseada em problemas mediada pela informática" e a dissertação de mestrado em Controladoria e Contabilidade Estratégica da Fundação Escola de Comércio Alvares Penteado (FECAP) de Irma Filomena Lobosco, em 2007, com o título "Caso-Problema no Ensino de Contabilidade Introdutória: Um Estudo da Percepção dos Alunos do Curso de Graduação quanto à sua Aplicabilidade no Desenvolvimento de Competências e Habilidades". Ao consultar a expressão "Problem Based Learning", foram apresentados apenas 25 trabalhos, nenhum título diferente do que já fora observado no banco de dados da Biblioteca Digital Brasileira de Teses e Dissertações do Ministério da Ciência e Tecnologia.

Calado e Silva Filho (2011) pesquisaram artigos relacionados à ABP na base de dados Compendex, em março de 2011, e encontraram 415 artigos em 45 diferentes países, considerando artigos publicados de 1969 a 2011. Concluíram que os artigos na base começaram a ser publicados na década de 80, mais precisamente em 1983 e o país com o maior número de publicações são os Estados Unidos com 64 artigos, seguido pela China, Taiwan, Reino Unido, Canadá, Japão, Malásia, Espanha, Austrália e Dinamarca. O Brasil apareceu na $23^{\mathrm{a}}$ posição com 4 artigos publicados.

Em pesquisa realizada na internet, um meio eficiente de busca de obras internacionais, foi observada uma única obra, dentre várias existentes sobre o método, voltada para a administração: "Problem Based Learning for Administrators", de Edwin M. Bridges, com a contribuição de Philip Hallinger, 
publicada no ano de 2002. O autor explica que, como docente, sempre se interessou em utilizar estratégias centradas em problemas para preparar futuros administradores, inicialmente com estudos de caso e mais recentemente (2002) com o a ABP e, por ser um método recém-chegado no campo da administração, decidiu escrever o livro, tanto na perspectiva conceitual como operacional, trazendo suas experiências, com erros e acertos.

O levantamento bibliográfico nos fez refletir sobre a necessidade da ampliação das pesquisas sobre a $\mathrm{ABP}$ no curso de Administração, a partir de três aspectos principais: 1. A prioridade de pesquisas e textos científicos que tratam especificamente de orientações para aplicação do método; 2 . A escassez de estudos no Brasil relacionados à ABP no referido curso; 3. A originalidade do nosso estudo que avaliou o método já empregado em uma Universidade, na concepção de docentes e discentes.

Assim, o mapeamento das pesquisas com a ABP nos revelou a necessidade da compreensão de outras fontes de informação para compreendermos tal metodologia no ensino superior. Consideramos que os documentos poderiam se constituir como um material primordial para atingir o objetivo principal da pesquisa. Passamos, agora, a relatar o encaminhamento da produção da análise documental.

Para que os documentos oficiais utilizados na instituição de ensino fossem cedidos, foi necessária uma autorização da direção, que aceitou oferecer toda e qualquer ajuda necessária para que o trabalho fosse realizado com a máxima qualidade. Os documentos levantados foram: Projeto Pedagógico do Curso de Administração, Orientações Gerais sobre o Plano de Ensino da Disciplina, Diretrizes Gerais para o desenvolvimento das disciplinas, Planos de Ensino, Planos de Aula, SituaçõesProblema, Formulário da Avaliação do processo educacional, Formulários de Relatório Parcial, Modelos de Relatório Final, Formulários de Autoavaliação do líder e avaliação dos pares, Critérios de Avaliação e Notas dos alunos.

O Projeto Pedagógico do Curso de Administração possui 188 páginas distribuídas em seis partes: 1. Organização didático-pedagógica; 2. Corpo docente, corpo discente e corpo técnico-administrativo; 3. Infraestrutura e instalações; 4. Avaliação; 5. Referência Bibliográfica; 6. Anexos. É no Projeto Pedagógico que constam informações importantes sobre a fundamentação teórico-metodológica da área com a adoção do método da ABP para o curso de administração e a proposta pedagógica. 
As Diretrizes Gerais dos anos de 2009 e 2010 contemplam as orientações de caráter geral, produzidas em decorrência de discussões realizadas durante as oficinas promovidas pela instituição com objetivo de aperfeiçoar as práticas pedagógicas.

Os Planos de Ensino trazem as seguintes informações: 1. Ementa; 2. Objetivos gerais da disciplina; 3. Objetivos específicos; 4. Conteúdo programático; 5. Metodologia; 6. Avaliação do processo de aprendizagem; 7. Critérios de avaliação; 8. Estratégias de recuperação; 9. Bibliografia básica; 10. Bibliografia complementar; 11. Infraestrutura e instalações. Os planos de aula apresentam o planejamento semanal dos conteúdos a serem abordados, o detalhamento destes conteúdos e os recursos que os docentes demandam.

A instituição pesquisada optou por inserir o método em uma estrutura de Eixos Temáticos e dentro deles, uma organização por disciplinas. Embora não seja o recomendável, por dificultar a interdisciplinaridade, não descaracteriza totalmente o conceito principal do método que tem por essência o uso de situações-problema e a pesquisa antecedendo a conceituação trazida pelo docente, promovendo o desenvolvimento de um trabalho colaborativo e cooperativo.

Para Cyrino e Toralles-Pereira (2004), no método da ABP são necessárias mudanças estruturais nos departamentos e disciplinas dos currículos, promovendo interdisciplinaridade, motivo pelo qual Tomaz (2001) não recomenda uma estrutura baseada em disciplinas. Young (2000), por sua vez, argumenta que falta coerência nos currículos não centrados em disciplinas uma vez que não é obedecida a relação entre currículo e procedimentos pedagógicos.

Como o objeto de estudo deste trabalho se dá na área financeira, que dentro da Matriz Curricular se apresenta no quarto período do curso, com as disciplinas de Matemática Financeira, Administração Financeira 1 e Administração Financeira 2, buscamos conhecer os Planos de Disciplina e com base nesses documentos, é possível observar que existe uma definição clara e bem organizada dos conteúdos trabalhados pelos docentes em cada uma das disciplinas. A área de finanças é trabalhada com 3 disciplinas e cada disciplina trabalha com 4 conteúdos, conforme o Quadro 1: 
QUADRO 1 - Disciplinas e conteúdos da área financeira

\begin{tabular}{|l|l|}
\hline Disciplina & Conteúdo Resumido \\
\hline Matemática Financeira & $\begin{array}{l}\text { 1) Juros Simples, Desconto Comercial e Taxa Proporcional } \\
\text { 2) Juros Compostos } \\
\text { 3) Taxas } \\
\text { 4) Fluxo de Caixa Homogêneo }\end{array}$ \\
\hline Administração Financeira 1 & $\begin{array}{l}\text { 1) Administrador Financeiro } \\
\text { 2) Mercado Financeiro e de Capitais } \\
\text { 3) Indinistração do Capital de Giro }\end{array}$ \\
\hline Administração Financeira 2 & $\begin{array}{l}\text { 1) Fluxo de Caixa Relevante } \\
\text { 2) Técnicas de análise de orçamento de capital } \\
\text { 3) Custo de capital } \\
\text { 4) Fontes de financiamento }\end{array}$ \\
\hline
\end{tabular}

Fonte: Os autores (2014).

Há que se considerar que o conhecimento da Proposta Pedagógica e do Plano de Ensino, por parte dos alunos, pode induzir a determinadas inferências do que é esperado no desenvolvimento dos trabalhos das disciplinas. Assim, é importante que o docente considere o fato para que não recaia em propostas de ensino com a formulação de situações-problema cujas respostas sejam facilmente identificadas pelos tópicos dispostos nos documentos oficiais da instituição.

As situações-problema são desenvolvidas pelos docentes e apresentadas aos discentes para que iniciem o processo de desenvolvimento do método. Existe um direcionamento sutil sobre os conteúdos a serem pesquisados pelos alunos e os textos permitem uma discussão inicial considerando os conhecimentos prévios dos alunos.

A origem da ABP demonstrou a necessidade de se trabalhar com as situaçõesproblema de forma interdisciplinar, desmontando as disciplinas sequenciais da matriz curricular, mas os estudos apontam que não há descaracterização do método se for aplicado no curso por áreas de conhecimento, como na instituição de ensino pesquisada, se obedecidas as fases do processo, como exemplo, o uso da estratégia dos "sete passos". A interdisciplinaridade não implica necessariamente em trabalhar com uma matriz curricular única, mas que seja exercida nas práticas pedagógicas. É definida por Garcia (2004, p. 44) como "um movimento exercido dentro das disciplinas e entre elas, visando integrá-las". 
Segundo Japiassu (1976), a interdisciplinaridade propõe uma reflexão crítica sobre a estrutura do conhecimento com o desejo de revitalizar o papel do professor na formação do corpo discente, sendo importante aprender a questionar seu modo de ensino e relações pedagógicas. Esse autor salienta que o professor interdisciplinar é aquele que possui domínio teórico e prático indelével em sua disciplina, mas também possui base para contribuir na articulação dos saberes de diversas disciplinas e é capaz de vislumbrar e explorar relações de interdependência das disciplinas.

O professor interdisciplinar possui habilidade para trabalhar em equipe, explorando focos de interesse comum e participando de projetos compartilhados. A interdisciplinaridade envolve a associação, colaboração, cooperação, complementação e integração entre as disciplinas, e os professores devem socializar não apenas seus conhecimentos, mas também suas experiências e visões do mundo (FAZENDA, 1979; GARCIA, 2004).

Embora haja a intencionalidade de trabalhar com a interdisciplinaridade, existe a fragilidade em relação à ausência de tempo por parte dos professores em conhecer todas as situações-problema do curso. Sugerimos a elaboração de uma situação-problema que possa ser utilizada em mais de uma disciplina, cada qual focalizando os estudos em sua área, e que os professores tenham um período de trabalho conjunto ao início de cada semestre, para rever e criar novas situaçõesproblema, que exigem tempo e dedicação.

O Professor 1 explicou que as situações-problema são estruturadas dentro do conteúdo programático constante no Plano de Ensino, no período do planejamento pedagógico, por uma equipe de professores com informações muito próximas da realidade do mercado, visando aproximar o discente da realidade profissional a ser enfrentada. Relatou que, embora os problemas devam ser aperfeiçoados, o tempo que os docentes dispõem para a criação de novas situações-problema a cada semestre é muito curto e, por este motivo, as mudanças não ocorrem com alta frequência.

Apresentar boas situações-problema é um desafio, já que elas não podem ser encontradas na literatura tradicional, portanto, demandam criatividade por parte dos professores. O Professor 2 acrescentou que a situação-problema só é levada aos alunos quando existe comum acordo entre os docentes sobre a forma e o conteúdo. Informou que algumas das situações-problema foram revistas para corrigir falhas, e ele acredita que sempre podem ser melhoradas. 
O Professor 3 ressaltou a importância da construção de uma situação-problema equilibrada, não podendo ser nem muito estruturada, com grande quantidade de informação, de modo que o discente não precise discutir o assunto e pesquisar. Nem muito aberta, com pouca informação, dificultando o desenvolvimento da tarefa e o trabalho de orientação do professor.

O Professor 4 frisou que todas as situações-problema passam por todos os professores envolvidos no processo para que possam criticá-las e aperfeiçoá-las, buscando maior qualidade do material a ser trabalhado com os discentes, ainda que os mesmos não se responsabilizem pela elaboração. Finalmente, o Professor 5 disse que a situaçãoproblema deve provocar a discussão do tema nos grupos, e permitir que os alunos desenvolvam uma postura de liderança na condução dos trabalhos e autonomia de pesquisa, com maior liberdade e menor interferência por parte do docente.

O formulário de avaliação do processo educacional foi utilizado na implantação do método, e no semestre seguinte foi descontinuado. Nesse formulário, os discentes avaliavam em escala - excelente, bom, regular ou insuficiente - cada situaçãoproblema quanto à motivação do grupo no desenvolvimento dos trabalhos, importância para a formação profissional, aquisição de novos conhecimentos, facilidade de obtenção de material, tempo para a realização das atividades, apresentação de resultados e realização dos objetivos do problema. Havia espaço para comentários sobre a avaliação efetuada e sugestões de melhoria. Os alunos ainda sintetizavam os conceitos aprendidos e enumeravam aqueles ainda obscuros.

Durante as observações realizadas em sala de aula da instituição pesquisada, foi possível identificar o processo apresentado na Figura 1, que consiste em quatro etapas. 
FIGURA 1 - Processo do PBL observado em sala de aula

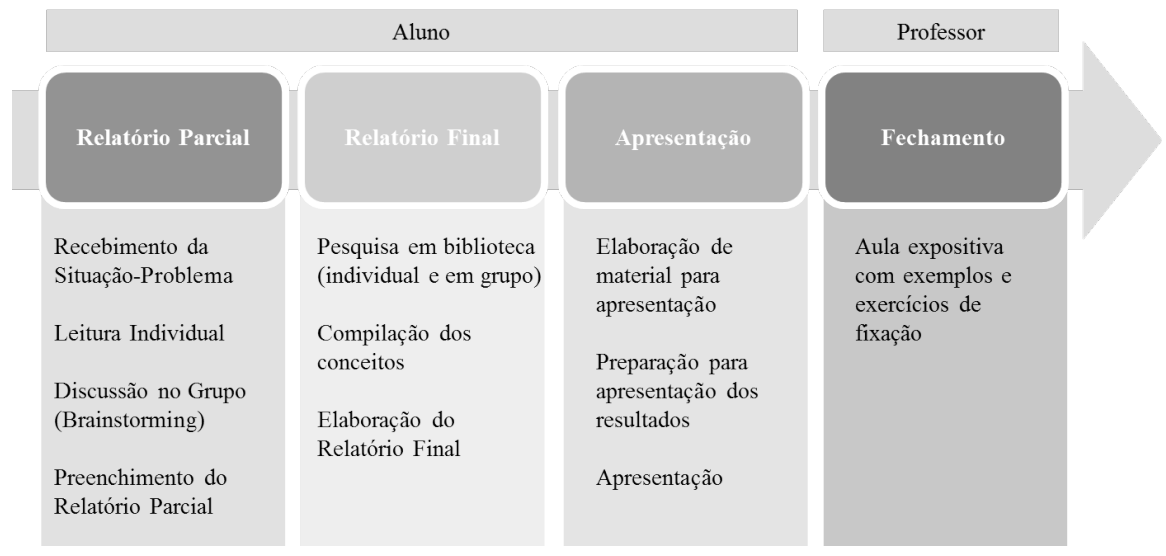

Fonte: os autores (2014).

Na primeira etapa, o docente apresenta a situação-problema aos grupos de alunos, que trabalham de forma cooperativa e colaborativa. É realizada a leitura e o desenvolvimento de um Relatório Parcial, que visa detalhar os pontos considerados relevantes e que demandam pesquisa conceitual. A segunda etapa consiste em pesquisa e elaboração de um Relatório Final com a apresentação dos conceitos pesquisados e a conclusão consensual do grupo. Na terceira etapa, os alunos socializam os seus resultados com toda a turma, apresentando as suas conclusões e o Relatório do Líder, que tem por finalidade apresentar o grau de comprometimento de cada participante do grupo com o resultado do trabalho. A quarta etapa consiste em uma aula expositiva do docente, visando solidificar o conhecimento adquirido e aprofundar os conceitos mais importantes.

O relatório parcial desenvolvido na primeira etapa foi apresentado em cinco diferentes modelos, diferenciando-os não apenas em layout, mas também em alguns conceitos. Ainda que existam diferenças, todos os modelos objetivam levar o aluno a refletir sobre a situação-problema, buscando a definição do problema, obtenção dos conhecimentos prévios dos alunos, percepção dos pontos mais importantes a serem destacados e, posteriormente, pesquisados em um planejamento de trabalho.

Para o relatório final, realizado após as pesquisas na segunda etapa do processo, dois modelos foram observados, ambos sugerindo que os alunos definam o problema e as estratégias de pesquisa, apontem os conceitos relevantes, indiquem 
as possíveis soluções e implicações éticas, apontem as referências bibliográficas e que seja formatado em conformidade com os padrões da Associação Brasileira de Normas Técnicas (ABNT).

A terceira etapa sugere o compartilhamento das conclusões e a integração dos conhecimentos adquiridos em uma explicação adequada. Para o Professor 4, muitos alunos têm dificuldade em expor o seu trabalho e a apresentação, como um passo importante do processo no método, permite que vençam as suas limitações. O Professor 2 informou que é feito, dentro dos grupos, um rodízio das tarefas e, desta forma, as chances de o aluno apresentar são majoradas, o que contribui significativamente com a sua formação.

Para o Professor 5, apesar de constar no Relatório Parcial a possibilidade de os alunos escolherem quem fará a apresentação, assumindo o papel de portavoz, ele combina com os alunos, desde o início das aulas, que a decisão ocorre no momento da apresentação, pois considera importante que todos tenham o conhecimento da matéria e que estejam preparados. Com essa medida, o professor busca certificar-se de que um maior número de alunos esteja estudando o que fora pesquisado por todo o grupo.

A definição prévia do porta-voz pode limitar o estudo do conteúdo ao responsável pela apresentação, desestimulando os membros-pesquisadores a se apropriarem de todo o conteúdo. Se a definição de quem representará o grupo ocorrer no momento da apresentação, ainda que não garanta o estudo, potencializa-o.

Em relação ao Relatório do Líder apresentado na conclusão da terceira etapa, foram coletados três diferentes modelos de autoavaliação do líder e avaliação dos pares, que diferem-se pelo layout e alguns conceitos, mas, em todos os modelos, o líder de grupo deve avaliar qualitativamente - excelente, bom, regular, insuficiente ou sem avaliação - os seguintes aspectos: 1) presença de cada membro do grupo nos encontros; 2) preparação para os encontros; 3) observação dos prazos estabelecidos e participação nas discussões dentro e fora da sala de aula; 4) respeito pelas opiniões dos membros do grupo; 5) contribuição para a organização do trabalho do grupo; 6) contribuição para a construção do consenso e realização das tarefas. Além disso, deve comentar a sua atuação como líder, informar as dificuldades encontradas pelo grupo e comentar a postura ética na realização dos trabalhos. 
O relatório de autoavaliação do líder e de seus pares é realizado de forma qualitativa, com atribuição de conceitos como excelente, bom, razoável, insuficiente e sem avaliação. Posto que o docente deva lançar notas quantitativas, é recomendável que após a reflexão qualitativa desenvolvida pelo líder, ele quantifique o resultado final de cada componente do grupo com uma nota que respeite o intervalo de zero a dez. Entendemos que a ausência de uma nota quantitativa pode resultar em um julgamento diferenciado de aluno e professor, minimizando a importância da avaliação realizada pelo aluno.

É de se imaginar que, na avaliação dos pares, o líder busque proteger os membros do seu grupo e os beneficiar com boas notas. Foram analisados 101 relatórios de um professor. Esses dados aparecem na Tabela 3.

Tabela 1 - Avaliação dos pares no Relatório do Líder por número de grupos

\begin{tabular}{|l|c|c|c|c|c|c|c|c|c|c|c|c|c|}
\cline { 2 - 13 } \multicolumn{1}{c|}{} & \multicolumn{4}{c|}{ Mat Fin } & \multicolumn{5}{c|}{$A F 2$} & \multicolumn{5}{c|}{$A F 2$} & \\
\cline { 2 - 13 } \multicolumn{1}{c|}{} & SP1 & SP2 & SP3 & SP4 & SP1 & SP2 & SP3 & SP4 & SP1 & SP2 & SP3 & SP4 & Total \\
\hline $\begin{array}{l}\text { Notas } \\
\text { iguais }\end{array}$ & 6 & 6 & 0 & 2 & 3 & 1 & 0 & 1 & 0 & 0 & 0 & 3 & 22 \\
\hline $\begin{array}{l}\text { Notas di- } \\
\text { ferentes } \\
\text { contendo } \\
\text { apenas B } \\
\text { ou E }\end{array}$ & 1 & 2 & 4 & 4 & 0 & 3 & 4 & 5 & 3 & 1 & 3 & 2 & 32 \\
\hline $\begin{array}{l}\text { Notas di- } \\
\text { ferentes } \\
\text { contendo } \\
\text { também } \\
\text { R, I ou S }\end{array}$ & 2 & 1 & 5 & 3 & 4 & 3 & 4 & 2 & 6 & 8 & 5 & 4 & 47 \\
\hline
\end{tabular}

$\mathbf{E}=$ Excelente $\mid \mathbf{B}=$ Bom $\mid \mathbf{R}=$ Regular $\mid \mathbf{I}=$ Insuficiente $\mid \mathbf{S}=$ Sem avaliação

Mat Fin = Matemática Financeira

AF 1 = Administração Financeira 1

AF 2 = Administração Financeira 2

SP = Situação-Problema

Fonte: Os autores (2014).

A maioria dos relatórios apontou diferenças de notas entre os membros dos grupos, atribuindo a pelo menos 1 integrante o conceito R (regular), I (insuficiente) ou S (sem avaliação).

Com esses resultados, é possível concluir que os alunos buscam, em maioria, realizar seus relatórios com coerência e senso de justiça.

Para compor a nota da disciplina, os alunos também realizam uma prova permitindo a avaliação individual do seu desempenho para que desenvolva 
melhor o seu potencial, podendo analisar de forma introspectiva seus erros e acertos. De acordo com Luckesi (2011), é importante que a avaliação não seja uma avaliação final, mas uma oportunidade para que o aluno possa diagnosticar falhas na construção do conhecimento e buscar reorientação para cumprir a principal finalidade da avaliação, que é promover um aprendizado satisfatório.

De acordo com o Professor 1, os resultados finais apresentados pelos alunos que se destacam durante o processo são positivos, e para aqueles que demonstram pouco interesse na matéria costumam ser medianos. Para o Professor 2, existe uma relação direta entre o desempenho do aluno ao longo do processo e a nota da prova.

\section{Considerações Finais}

A ABP, quando empregada no Ensino Superior, pode ser definida de forma mais simples como um método de ensino-aprendizagem cooperativo e colaborativo, que insere o aluno em uma realidade próxima ao que enfrentará no mundo profissional, permitindo o desenvolvimento dos conteúdos conceituais, procedimentais e atitudinais por meio de situações-problema. Pelas suas características particulares, como o trabalho em grupo, relacionamento mais próximo com o docente, promoção da autonomia e pela própria dinâmica de trabalho, é uma alternativa interessante para atender aos anseios de uma geração tecnológica, ousada e desafiadora.

É importante que os professores conheçam os fundamentos pedagógicos e filosóficos do método para que não desenvolvam-no sem o conhecimento profundo da relação existente entre cada ferramenta utilizada ao longo do processo com as práticas pedagógicas, considerando, desde a estratégia de formação dos grupos e a criação das situações-problema, até o desenvolvimento dos relatórios e avaliações.

Consideramos que, para novas pesquisas seja importante a verificação dos resultados que serão apresentados na avaliação externa do ENADE, realizada em novembro de 2012, para que seja observada a influência da aplicação da referida metodologia com relação ao conteúdo conceitual. Parece-nos também relevante o acompanhamento dos alunos após a conclusão do curso.

Dado que o presente trabalho foi desencadeado pela inquietação do pesquisador com relação à própria prática, julgamos que o mesmo serviu para apresentar elementos que permitissem a reflexão sobre o desenvolvimento pessoal e profissional, 
propiciando a compreensão dos fundamentos do método para a aplicação junto aos discentes. É um material que servirá, também, como contribuição para a prática docente dos professores que participaram da pesquisa ao entrarem em contato com os resultados apresentados, para a direção de faculdade, que poderá utilizá-la como ferramenta para reflexão sobre o processo atualmente aplicado, e para novos pesquisadores que vierem a se interessar pela utilização do método.

\section{Referências}

ANDRADE, E. N. F.; CUNHA, M. V. Discursos e auditórios: análise retórica dos argumentos de Dewey e Aristóteles acerca do homem e do desenvolvimento humano. Revista Educação e Cultura Contemporânea, Rio de Janeiro, v. 8, n. 17, p. 1-25, 2011.

ATRIE, D. et al. Approaching PBL Practically: a guide for students by students. Michael G. de Groote School of Medicine, 2009. Disponível em: <http://fhs. mcmaster.ca/facdev/documents/ApproachingPBLPracticallySept.08.pdf.>. Acesso: 23 set. 2012.

BRANDA, L. A. A aprendizagem baseada em problemas - o resplendor tão brilhante de outros tempos. In: ARAÚJO, U. F.; SASTRE, G. Aprendizagem baseada em problemas no Ensino Superior. São Paulo: Summus, 2009.

BRIDGES, E. M. Problem based learning for administrators. ERIC Clearinghouse on Educational Management. University of Oregon, 1992.

CALADO, R. D.; SILVA FILHO, O. S. Abordagem PBL utilizando relatório A3 com aplicação à disciplina administração da cadeia de suprimento. In: SILVA, L. B. de O.; BARCELlOS, A. C. K.; MARCON, G. Br. (Org.). Dilemas da Educação no Século XXI: refletindo acerca de metodologias, ensino e pesquisa. São Carlos: Pedro \& João Editores, 2011. p. 77-95.

CANDAU, V. M. (Org.). Reinventar a Escola. Petrópolis: Vozes, 2000.

CARLINI, A. L. Aprendizagem baseada em problemas aplicada ao ensino de direito: Projeto exploratório na área de relações de consumo. 2006. 295 f. Tese (Doutorado em Educação), Pontifícia Universidade Católica de São Paulo, São Paulo, 2006. 
CHIZZOTTI, A. Pesquisa qualitativa em ciências humanas e sociais. Petrópolis: Vozes, 2010.

CYRINO, E. G.; TORALLES-PEREIRA, M. L. Trabalhando com estratégias de ensino-aprendizado por descoberta na área da saúde: a problematização e a aprendizagem baseada em problemas. Cadernos de Saúde Pública, Rio de Janeiro, v. 20, n. 3, p. 780-788, 2004.

DEELMAN, A.; HOEBERIGS, B. A ABP no contexto da universidade de Maastricht. In: ARAÚJO, U. F.; SASTRE, G. (Orgs.). Aprendizagem Baseada em Problemas no Ensino Superior. São Paulo: Summus, 2009. p. 79-100.

DELISLE, R. How to Use Problem-Based Learning in the Classroom. Alexandria, Virginia: Association for Supervision \& Curriculum Deve, 1997.

DEWEY, J. Democracia e Educação: introdução à filosofia da educação. 3. ed. São Paulo: Companhia Editora Nacional, 1959.

.Experiência e Educação. 2. ed. São Paulo: Companhia Editora Nacional, 1976.

. Vida e Educação. 10. ed. São Paulo: Melhoramentos, 1978.

FAZENDA, I. Integração e interdisciplinaridade no ensino brasileiro: efetividade ou ideologia? São Paulo: Loyola, 1979.

FLINT, W. J. Problem-based Learning: welcome to the real world: a teaching model for adult learners. Charleston, South Carolina: BookSurge Publishing, 2007.

FONSECA, V. Aprender a aprender: a educabilidade cognitiva. Porto Alegre: Artmed, 1998.

GARCIA, J. Notas sobre o professor interdisciplinar. Educação Temática Digital, Campinas, v. 5, n. 2, p. 42-57, jun. 2004.

GIL, A. C. Como elaborar Projetos de Pesquisa. São Paulo: Atlas, 2002. 
GODOY, A. S. Revendo a aula expositiva. In: MOREIRA, D. A. (Org.). Didática do ensino superior: técnicas e tendências. São Paulo: Pioneira, 2000. p. 75-82.

HARGREAVES, A. O ensino como profissão paradoxal. Pátio: revista pedagógica, Porto Alegre, ano 4, n. 16, p. 13-18, fev./abr. 2011.

JAPIASSU, H. Interdisciplinaridade e patologia do saber. Rio de Janeiro: Imago, 1976.

LEVIN, B. Energizing teacher education and professional development with problem-based learning. ASCD: United States, 2001.

LOURENÇO, R. S.; PALMA, A. P. T. V. O conflito cognitivo como princípio pedagógico no processo ensino-aprendizagem nas aulas de educação física. Revista de Educação do Cogeime, ano 14, n. 27, dez./2005. p. 43-54.

LUCKESI, C. C. Avaliação de aprendizagem: componente do ato pedagógico. São Paulo: Cortez, 2011.

MAMEDE, S. Aprendizagem baseada em problemas: características, processos e racionalidade. In: MAMEDE, S.; PENAFORTE, J. (Org.). Aprendizagem baseada em problemas: anatomia de uma nova abordagem educacional. Fortaleza: Hucitec, 2001. p. 25-48.

MARCONI, M. A.; LAKATOS, E. M. Técnicas de pesquisa. São Paulo: Atlas, 2007.

MEIRIEU, P. Aprender... Sim, mas como? 7. ed. Porto Alegre: ArtMed, 1999.

MENNIN, S et al. Position paper on problem-based learning. Education for Health, v. 16, n. 1, p. 98-113, 2003. Disponível em: < http://www.educationforhealth. net/EfHArticleArchive/1357-6283_v16n1s17_713665182.pdf >. Acesso em: 23 set. 2012.

MUNRO, C. R. Mentoring needs and expectations of generation-Y. Human resources practitioners: preparing the next wave of strategic business partners. Journal of Management Research, v. 1, n. 2, 2009. 
NEVES, A. C. Reflexões sobre o ensino superior de contabilidade e a formação do contador. Revista do Conselho Regional de Contabilidade do Rio Grande do Sul, Rio Grande do Sul, p. 18-29, abr. 2006.

PENAFORTE, J. C. John Dewey e as raízes filosóficas da aprendizagem baseada em problemas. In: MAMEDE, S.; PENAFORTE, J. (Org.). Aprendizagem baseada em problemas: anatomia de uma nova abordagem educacional. Fortaleza: Hucitec, 2001. p. 49-78.

PEREIRA, E. M. A. Professor como pesquisador: o enfoque da pesquisa-ação na prática docente. In: GERALDI, C. M. G. et al. (Org.). Cartografias do trabalho docente: professor(a)-pesquisador(a). Campinas: Mercado das Letras, 1998. p. 153-181.

POZO, J. I. Aprendizes e mestres: a nova cultura da aprendizagem. Porto Alegre: Artmed, 2002.

QUADROS, A. L. et al. A percepção de professores e estudantes sobre a sala de aula de ensino superior: expectativas e construção de relações no curso de química da UFMG. Ciência e Educação, São Paulo, v. 16, n. 1, p. 103-114, 2010.

RIBEIRO, L. R. C. A aprendizagem baseada em problemas (PBL): uma implementação na educação em engenharia na voz dos atores. 2005. 209f. Tese (Doutorado em Educação), Universidade Federal de São Carlos, São Carlos, 2005.

RIBEIRO, L. R. C. Aprendizado baseado em problemas. São Carlos: UFSCAR; Fundação de Apoio Institucional, 2008.

RODRIGUES, M. L. V.; FIGUEIREDO, J. F. C. Aprendizado centrado em problemas. Medicina, Ribeirão Preto, v. 29, p. 396-402, out./dez. 1996.

RUIZ, J. A. Metodologia Científica: guia para eficiência nos estudos. São Paulo: Atlas, 2002.

SALVADOR, C. C. et al. Psicologia da educação. Porto Alegre: Artes Médicas Sul, 1999. 
SAMPIERI, R. H.; COLLADO, C. F.; LUCIO, P. B. Metodologia de pesquisa. São Paulo: McGraw-Hill, 2006.

SOARES, M. A. Aplicação do método de ensino Problem Based Learning (PBL) no curso de Ciências Contábeis: um estudo empírico. 2008. Dissertação (Mestrado em Controladoria e Contabilidade), Faculdade de Economia, Administração e Contabilidade de Ribeirão Preto, Universidade de São Paulo, Ribeirão Preto, 2008.

TIBALLI, E. F. A. Pragmatismo, experiência e educação em John Dewey. Poços de Caldas: ANPEd, 2003.

TOMAZ, J. B. O desenho de currículo. In: MAMEDE, S.; PENAFORTE, J. (Org.). Aprendizagem baseada em problemas: anatomia de uma nova abordagem educacional. Fortaleza: Hucitec, 2001. p. 109-139.

VIANA, M. D. A. O que anseiam os jovens trabalhadores?: valores e expectativas da geração Y acerca do trabalho. Rio de Janeiro: Pontifícia Universidade Católica do Rio de Janeiro, 2011.

YOUNG, M. F. D. O currículo do futuro: da nova sociologia da educação a uma teoria critica do aprendizado. Campinas: Papirus, 2000.

ZABALA, A. A prática educativa: como ensinar. Porto Alegre: Artmed, 1998.

ZUCCO, A. Estilos de mobilização profissional de docentes de cursos de graduação em administração. São Caetano do Sul: USCS, 2010. 


\section{Problem-Based Learning: a method of teaching and learning and their educational practices Abstract}

The Problem-Based Learning method aims to make students capable of building their knowledge in conceptual, procedural and attitudinal ways by posing problems that will introduce them to situations designed to motivate them and prepare them for the working world. We analyze the development of the method in the course of administration of a university of the state of São Paulo, specifically the disciplines of finance, involving theoretical and mathematical concepts. We use four instruments in data collection: document analysis, interviews with teachers, principals and former acting director; questionnaire with students and observation, and for this article we bring the theoretical assumptions of that method, document analysis and interview with all professors of finance, who brought their experiences in the classroom. The results indicate that it is necessary to improve teaching practice.

Keywords: Evaluation. Higher education. PBL.

\section{Aprendizaje Basado en Problemas: un método de enseñanza- aprendizaje y sus prácticas educativa Resumen}

El método de Aprendizaje Basado en Problemas (ABP) tiene por objeto ayudar al alumno a construir un aprendizaje conceptual, procedimental y actitudinal a través de problemas propuestos que lo exponen a situaciones motivadoras y lo preparan para el mundo laboral. Para tal fin, se analiza el desarrollo del método en el curso de Administración de una universidad provincial de San Pablo, Brasil, especificamente, en las asignaturas relativas a las finanzas que involucran conceptos teóricos y matemáticos. Se utilizan cuatro instrumentos en la recolección de datos: análisis documental; entrevistas con profesores, ex-directores y el director actual; cuestionario con alumnos y su observación respectiva. También se presentan informaciones sobre los presupuestos teóricos del método mencionado, del análisis documental y algunas entrevistas con los profesores del área temática de finanzas, que expusieron sus experiencias del aula. Los resultados obtenidos señalan que es necesario el perfeccionamiento en la práctica docente.

Palabras-clave: Evaluación. Enseñanza Superior. ABP. 